\title{
INFORMATION SEEKING BEHAVIOUR THROUGH INTERNET TECHNOLOGY IN LIBRARY USERS, CHIDAMBARAM TOWN
}

\author{
Dr. R. Kavitha1, Dr. S. Aravind ${ }^{2}$ \\ ${ }^{1}$ Assistant Librarian (Deputed Staff), Mother Teresa Women's University, \\ Kodaikanal, Dindigul District \\ Email: kavitharamalar@gmail.com \\ ${ }^{2}$ Librarian and Head, \\ Central Library E Department of Library and Information Science, \\ G.T.N. Arts College (Autonomous), Dindigul, Tamilnadu, India. \\ Email:aragtn2601@yahoo.com
}

\section{Manuscript Info Abstract}

\section{Manuscript History}

Received: 10 October 2020

Final Accepted: 24 November 2020

Published: 10 December 2020

Online Published: January 2021

DOI: http:/ /dx.doi.org/10.35337/EIJLITR.2021.1103

Corresponding Author's E-mail:

kavitharamalar@gmail.com

aragtn2601@yahoo.com

(c) Dr. R. Kavitha, Dr. S. Aravind The Authors. This is an open access article under the terms of the Creative Commons Attribution License 4.0, which allows use, distribution and reproduction in any medium, provided the original work is properly cited.

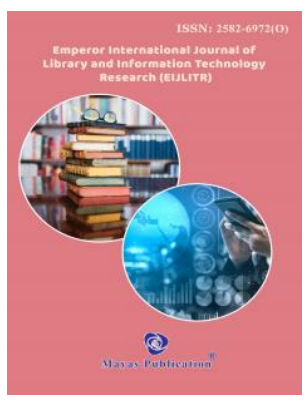

The field of library and information looks at an is a remarkable interdisciplinary area of study, drawing as it does upon, for instance, the heads considers, programming designing correspondence studies and librarianship similarly as periphery subjects, for instance, Psychology, Linguistics and bits of knowledge to be viable in library and information mulls over must be envisioned as an authentic, composed and sensible whole while holding a versatility and responsiveness to change. Moreover, LIS tutoring and getting ready must consolidate a strong realistic section which must be totally given food to inside the instructive program. The arranging of instructive projects for this irrefutably huge subject which needs in different settings thought or denial of explicit topics and once in a while offering emphasis to certain individual focuses, for instance, information Technology is tangled and complex. The current examination intends to find the information searching for direct through web development in library customers, Chidambaram town. An instances of 125 library customers picked self-assertively were thought of. Basic data were accumulated by using a coordinated gathering booked. All the library customers were represented the a couple of requests in a comparative style and they were taught the explanation with respect to examine. 
Cross association and Chi-square test were applied to test the hypotheses. The disclosures and observations are the result a lot of the understandings made during the examination of assessment.
Keywords: Internet Technology, Information Seeking Behavior, Search Engine and Portion Variables

\section{INTRODUCTION}

The library and information Science schools everything considered in the whole of what countries have been accepting the instructive plans solidifying the continuous upgrades happening in the region of the snappy making subject. The library schools in the made countries have been rethinking the instructive program so customarily as to address the new challenges in the information world. However, such alteration of the instructive arrangement the library schools in India has not been frequently endeavored by the library colleges to meet the movements happening in the information world. Without a doubt the library colleges in India couldn't keep awake with the amendment of instructive program due to number of parts. This situation makes a lot of bewildering between the work delivered from library colleges and the genuine work essentials in the various types of libraries and information. In 1969, the US division of protect made an association called the ARPA net, (Advanced Research Project Agency). In light of gigantic development in the use of ARPA net for non-military purposes, the US division of assurance made an exclusively military association called MIL net. Two or three years sometime later National Science Foundation molded the NSF net, near anyway snappier than ARPAnet which associated together NSF investigates. Around then there where no PCs. The model, the huge incorporated worker sat at the point of convergence of a starfish-interface system with an idiotic terminal (a CRT) and a watchword at the tip of each arm. Web is association of PCs that offers information and permission to people. "Web" was wrote from the word" Inter affiliation" and "associations", such association of associations is arranged "Web".

\section{Advantages of Internet Based Service}

The essential inclinations of Internet organizations are according to the accompanying.

$>$ The caretaker can serve even the far away customers sitting at his reference work region.

$>$ The customers can a reference request through email.

$>$ The customers can scrutinize the particular site for his/her need.

$>$ The User's time can be saved for the most part..

$>$ Current and forefront information can be given.

\section{Internet, the Information Super Highway}

Web is an arrangement of Networks, a beast understanding among, an immense number of PC systems to interface together. It contains.

> Government Computers, controlled by nations all through the world.

$>$ Computers run by numerous different Universities and schools.

$>$ Systems having a spot with non-advantage Organizations that basically need to bring web enrolling "to the people".

$>$ Computers controlled by business endeavors that acquire money by giving people induction to this bewildering cover related structure.

The Internet interfaces countless people all through the world, from Russia to Rhode Island, Austria to Australlia. Once on this structure if we know where we are going and how to show up we can journey around in Cyberspace, going from PC to PC, terrain to landmass.

\section{REVIEW OF LITERATURE}

A. Prentice (2012), made an assessment on "Information searching for instances of picked specialists using electronic media". J.Paisley and a Hardy coordinated the report on the experts and their uses and needs were submitted in 2012. The standard of investigation on the improvement were examined in their 
report. On customer studies and information needs", was investigated by T.D.Wilson in 2012. One year from now Mr. H.L. Shuchman, focused on "Information Technology and the Technologist" which the assessment was made on American authorities.

Claire, Guichat, Michael and Menou (2012) revealed that the general course and plan of information units and system for reliably found on the searchers and should reflect their characteristics, mindsets, needs and demands in the examination of "Customer packs all things considered preamble to the techniques for information and documentation work".

The customer needs and their desire in each center were concentrated by B.Dervin and M.Nilan (2013), entitled on "Information needs and customers". A.R. Sethi nitty gritty in his assessment "Information Seeking Behavior of Area Specialists using web" as the customer's fulfillment and satisfaction in their searching for data in information networks during the year.

L. Westbrook (2013) had made an assessment on the customers which named on "Customer needs: a blend and examination for the master". Mr.T.M.Tanner had made assessment on specialists as "What pastors know: A quality examination of priests as information specialists" in 2013.

The information searchers demands their disappointments, dispensing with the preventions are destitute somewhere around W.Tom, (2014) entitled on "Information needs and uses", from the 50 years of assessment on customer network submitted in the year 2014.

In 2015 the assessments on specialists like planners and customers were made by G.J. Leckie and K.E. Pettigrew, named on "Showing the information searching for of specialists: a general model got from research on engineers and customers".

C.A. Barry and D. Associates (2015) made the astounding revelations on "why the move from the ordinary information searching for lead to the electronic library (web) isn't straight forward for educational customers in 2015 in London.

S.Harikrishnna Reddy and C.R. Karisiddappa (2016) were driven the investigation on master in their India in the year 2016, named on "Information Seeking Behavior Professionals by using web in India", was circulated in Annual for library science and documentation. In the very year T.D. Wilson made the survey on the specialists entitled on "Information Behavior: An Inter-disciplinary Perspective", and Terry Mohan had analyzed the speculation and practice in correspondence conquering the information places was brought out in Sydney, entitled on "Giving: Theory and practice".

In the assessments on the specialists of genuine scientists coordinated by S.Jange and B.S. Madeshwarappa (2016) purpose of giving the reference to Gubbarya University, entitled on "Information Seeking Behavior of Physical Scientists using web". The researcher perceived that prevailing piece of them are interested to search for their information by using web. They feel it is the most easy cycle when appeared differently in relation to the regular procedure for library use.

Ashu Shokeen and Sanjay K. Kausik (2017) investigated the information searching for direct of social analysts working in the Universities arranged in Harayana. The data was assembled through a structure survey. The outcomes of the assessment showed that periodicals are the most used and huge wellsprings of information.

\section{OBJECTIVES OF THE STUDY}

$>$ To know the purpose behind Internet examining.

$>$ To acknowledge which web files used for web.

$>$ To find which sort of tutoring bundle use web more.

$>$ To find which sort of web account that the customer have. 


\section{METHODOLOGY}

Investigation strategy is a way to deal with productively deal with the assessment issue. It may be seen as an investigation of concentrating how assessment is done consistently. In it, we study the various advances that are usually grasped by a researcher in analyzing his assessment issue close by the reasoning behind them. The arranging of the investigation setup, appropriate for a particular assessment issue incorporates generally the idea of the going with; The strategies for getting the information; The availability and capacities of the investigator and his staff (expecting any); Explanation of the way picked techniques for procuring information will be facilitated and the reasoning provoking the decision; The time open for research; The cost factor relating to explore, i.e., the record available for the explanation. Investigation design is needed considering the way that it supports the going incredible of the distinctive assessment undertakings, in this way making research as beneficial as possible yielding maximal information with immaterial utilization of effort, time and money.

$>$ The inspecting plan which deals with the method for picking things to be seen for the given assessment;

$>$ The observational arrangement which relates to the conditions under which the discernments are to be made;

$>$ The quantifiable arrangement, which stresses with the strategies by which the frameworks decided in the testing, real and recognition plans can be finished.

Investigation design is needed in light of the fact that it energizes the going incredible of the distinctive assessment assignments, appropriately making research as capable as possible yielding maximal information with irrelevant utilization of effort, time and money.

\section{Method of Data Collection}

The basic data are those which are accumulated by the researcher. The discretionary data, of course, are those which have quite recently been assembled by someone else and which have quite recently been experienced the genuine cycle. The researcher would need to pick which sort of data he will use for his examination and moreover, he ought to pick either method for data collection. The procedures for social affair fundamental and helper data differ since basic data are at first assembled while if there should be an event of discretionary data, the possibility of data variety work is just that of conglomeration. There are a couple of various methods of get-together the fitting data which fluctuate altogether in setting of money, time and various resources at the evacuation of the researcher. Fundamental data can be assembled either through examination or through survey. If the expert coordinates an assessment, he sees some quantitative assessments, or the data, with the help of which the researcher reviews reality contained in his hypothesis. However, because of a diagram, the going with ways are used to assemble the data.

\section{By Observation}

This strategy proposes the grouping of information through expert's own discernment, without meeting the library customers. The information gained relates to what is correct now happening and isn't tangled by either the past lead or future objectives or points of view of library customers. This procedure is no vulnerability an exorbitant method and the information gave by this technique is also incredibly limited. As such this system isn't fitting in solicitations where colossal models are concerned.

\section{Through personal interviews}

The authority follows an unyielding procedure and searches for answers to a lot of pre-thought about requests through near and dear gatherings. This method for social occasion data is typically done in a coordinated way where yield depends on the limit of the examiner to a colossal degree.

\section{Selection of Library users}

Web customers of this Chidambaram town were the reviewing unit of this examination. Self-assertive examining methodology was followed for picking the library customers. Considering the limitation of resources like time and money a model size of 125 customers in Chidambaram town was settled. 
Analysis and Discussions

TABLE 1

CROSS TABULATION FOR THE PLACE WHERE THE RESPONDENTS ACCESS INTERNET \& E-MAIL

\begin{tabular}{|l|c|c|c|c|c|c|c|}
\hline Opinion & At the browsing center & At office institution & Technical center & Total & $\mathbf{X}^{\mathbf{2}}$ & DF & LS \\
\hline Yes & 15 & 9 & 5 & 29 & & & \\
No & 63 & 29 & 4 & 96 & 3.4 & 2 & NS \\
\hline Total & 78 & 38 & 9 & 125 & & & \\
\hline
\end{tabular}

Hy : Male and Female respondents contrast in their place of scrutinizing.

It is seen from the table $15 \%$ of them use scrutinizing center, $9 \%$ of them use office and $4 \%$ of them specific core interest. However, it isn't attested genuinely because is non gigantic. So the communicated hypothesis is excused.

TABLE 2

CHI-SQUARE TEST BETWEEN RESPONDENTS GENDER AND THEIR USAGE TIME

\begin{tabular}{|l|c|c|c|c|c|l|l|l|}
\hline Sex & $\mathbf{2}$ hours & $\mathbf{5}$ hours & $\mathbf{1 0}$ hours & More then 10 hours & Total & $\mathbf{X}^{\mathbf{2}}$ & DF & LS \\
\hline Male & 35 & 35 & 10 & 2 & 82 & & & \multirow{2}{*}{$15 \%$} \\
\cline { 1 - 7 } Female & 22 & 11 & 9 & 1 & 43 & \multirow{2}{*}{3} & $5 \%$ \\
\hline Total & 57 & 46 & 19 & 3 & 125 & & & \\
\hline
\end{tabular}

Hy: Male and Female respondents contrast in their scrutinizing time.

It is seen from the table that $70 \%$ of male experience Internet to 5 hours. However, $33 \%$ of female use Internet upto 5hours.On the whole male use more than female respondents. This differentiation in verifiably showed with the help of gained Chi-square worth, (15.45) which is basic at $5 \%$ and $1 \%$ level. In this manner the communicated hypothesis recognized.

TABLE 3

\section{CHI-SQUARE TEST BETWEEN RESPONDENT'S EDUCATION AND THEIR} INTERNET USAGE HOURS

\begin{tabular}{|l|c|c|c|c|c|c|c|c|}
\hline Education & 2 hours & 5 hours & 10 hours & More then 10 hours & Total & $\mathbf{X}^{\mathbf{2}}$ & DF & LS \\
\hline PhD & 23 & 21 & 4 & 0 & 48 & & & \\
BE & 11 & 15 & 4 & 2 & 32 & & & \\
ME & 16 & 10 & 6 & 2 & 34 & \multirow{2}{*}{24.5} & \multirow{2}{*}{12} & $1 \%$ \\
\hline MBA & 7 & 3 & 1 & 0 & 11 & & & \\
\hline Total & 57 & 49 & 15 & 4 & 125 & & & \\
\hline
\end{tabular}

Hy : There is a basic differentiation between the respondent's tutoring and their level of Internet use.

The table reveals that Ph.D qualified respondents use Internet more than the other qualified respondents. MBA qualified respondents similarly use extra time when appeared differently in relation to other qualified respondents. This qualification is verifiably attested by the got Chi-square worth, which is colossal at $5 \%$ and $1 \%$ level. In this manner the communicated hypothesis is recognized. 
TABLE 4

CHI-SQUARE TEST BETWEEN RESPONDENTS EDUCATION AND THEIR INTERNET USAGE HOURS

\begin{tabular}{|l|c|c|c|c|c|c|c|c|}
\hline \multicolumn{1}{|c|}{ Age } & 2 hours & $\mathbf{5}$ hours & $\mathbf{1 0}$ hours & More then 10 hours & Total & $\mathbf{X}^{\mathbf{2}}$ & DF & LS \\
\hline Less then 25 & 28 & 19 & 7 & 2 & 56 & & & \\
\cline { 1 - 8 } 26-35 & 12 & 18 & 5 & 3 & 38 & \multirow{3}{*}{20.5} & \multirow{3}{*}{9} & $5 \%$ \\
\hline 36 and above & 14 & 15 & 2 & 0 & 31 & & & \\
\hline Total & 54 & 52 & 14 & $5 \mathrm{~s}$ & 125 & & & \\
\hline
\end{tabular}

Hy : Respondents don't differentiate in their web usage hours dependent on preparing.

It is seen from the table that under 25 years use web more than the other age bundles This differentiation is confirmed by the procured result. which is basic at $5 \%$ level. So the communicated hypothesis is excused.

TABLE 5

RESPONDENTS EDUCATION AND THEIR PURPOSE INTERNET USE

\begin{tabular}{|c|c|c|c|c|c|c|c|}
\hline Education & $\begin{array}{l}\text { Education } \\
\text { academic }\end{array}$ & Business & Informatics & $\begin{array}{l}\text { If any other, kindly } \\
\text { specify }\end{array}$ & $\mathrm{X}^{2}$ & DF & LS \\
\hline $\mathrm{PhD}$ & 23 & 14 & 11 & 48 & \multirow{5}{*}{22.15} & \multirow{5}{*}{9} & \multirow{5}{*}{$5 \%$} \\
\hline $\mathrm{BE}$ & 11 & 15 & 6 & 32 & & & \\
\hline $\mathrm{ME}$ & 22 & 10 & 2 & 34 & & & \\
\hline MBA & 7 & 1 & 3 & 11 & & & \\
\hline Total & 63 & 40 & 22 & 125 & & & \\
\hline
\end{tabular}

Hy: There is a basic difference between the respondents preparing and their inspiration Internet use.

It is seen from the table that autonomous of their tutoring level $63 \%$ of them use Internet for guidance reason, $40 \%$ of them use Internet for Business. Simply $22 \%$ used for information. This qualification quantifiably attested by the Chi-square test. So the communicated hypothesis is recognized.

TABLE 6

RESPONDENT'S EDUCATION AND THE SEARCH ENGINES USED

\begin{tabular}{|l|c|c|c|c|c|c|c|}
\hline Education & Msn & Yahoo & AltaVista & Total & $\mathbf{X}^{\mathbf{2}}$ & DF & LS \\
\hline PhD & 23 & 16 & 9 & 48 & & & \\
BE & 14 & 10 & 8 & 32 & & & \multirow{2}{*}{19.2} \\
ME & 16 & 12 & 6 & 34 & 5 & $5 \%$ \\
\hline MBA & 7 & 2 & 2 & 11 & & & \\
\hline Total & 60 & 40 & 25 & 125 & & & \\
\hline
\end{tabular}

Hy: There is a tremendous difference between the respondents preparing and the web crawlers used.

It is seen from the table that free of their tutoring 60 of the respondents used MSN web crawler, 40 of them used Yahoo and 20 of them used Altavista for web scrutinizing. So larger portion of them used MSN and Yahoo. This qualification is in a general sense attested by the got Chi-square worth, which is basic at $5 \%$ and $1 \%$ level. In this way the communicated hypothesis is recognized. 
TABLE 7

RESPONDENTS GENDER AND THE TYPE OF INTERNET SERVICE PROVIDER THEY USED

\begin{tabular}{|l|c|c|c|c|c|c|c|c|}
\hline \multicolumn{1}{|c|}{ Sex } & Vsnl & Satyam online & Pronet & Others & Total & $\mathbf{X}^{2}$ & DF & LS \\
\hline Male & 28 & 41 & 10 & 3 & 82 & & & \\
\cline { 1 - 7 } Female & 24 & 11 & 6 & 2 & 43 & 18.2 & \multirow{3}{*}{5} & $5 \%$ \\
\hline Total & 52 & 52 & 16 & 5 & 125 & & & \\
\hline
\end{tabular}

Hy : There is an enormous qualification between the respondents sex and such an Internet expert center used.

It is found from the table that free their sex larger portion of them used Satyam Online (41.6\%) followed by VSNL $(41.6 \%)$, Pronet $(12.8 \%)$ and others $(4 \%)$.This differentiation is quantifiably exhibited with the help of Chi-square test, which is basic at $1 \%$ and $5 \%$ level. In this way the communicated theory is recognized.

TABLE 8

\section{CHI-SQUARE TEST FOR USAGE OF INTERNET FOR E-MAIL ON THE BASIS OF GENDER}

\begin{tabular}{|l|c|c|c|c|c|c|}
\hline \multicolumn{1}{|c|}{ Sex } & Yes & No & Total & $\mathbf{X}^{\mathbf{2}}$ & DF & LS \\
\hline Male & 52 & 30 & 82 & & \multirow{3}{*}{1} & \multirow{2}{*}{$1 \%$} \\
\cline { 1 - 4 } Female & 32 & 11 & 43 & \multirow{2}{*}{12.5} & \multirow{2}{*}{$1 \%$} \\
\cline { 1 - 4 } Total & 84 & 41 & 125 & & & \\
\hline
\end{tabular}

Hy: Male and Female differences in their inspiration of Internet.

It is assembled from the table that autonomous of the sexual direction $67.2 \%$ of them used web for E-mail and $32.8 \%$ of them says they are used web for other explanation. This differentiation is quantifiably shown by the chi-square test. So the communicated hypothesis is recognized.

\section{CONCLUSION AND IMPLICATIONS}

It is seen that believe it or not, very few of the general population used PCs, it is an immediate aftereffect of significant expense. So the authority proposed to the associations endeavor to reduce the expense. With the objective that such a people used PCs and in this manner information development will improved. It is moreover found that most of the customers used web simply less hours, because the telephone bill is high. So the concerned office endeavor to diminish the cost. From that all people endeavor to use more hours. As needs be they get more information and their knowledge also improved. It is moreover observed that indeed, very few of them use E-mail, this is a result of nonattendance of data. So the enlightening establishments direct care program related to web and its application. If these things are executed the web customers masses are to extended. The result found that by far most of the customers used only a specific web crawlers for web considering the way that sufficient information they get from those engines. In this manner other web files are similarly used to assemble more informations. From the examination it is found that most of the respondents give issue, in the web they are not getting the information in a proper game plan. So the concern affiliation endeavor to improve the plan. So the customers get the vital information with no issue. 


\section{REFERENCES}

1. Ashu Shokeen and Sanjay K. Kausik (2017) "Users responses to and knowledge about an online catalogue". College and Research Libraries, 45, January, pp.66-70.

2. Barry C.A. and D. Squires (2015). "Net Applications: Will Netscape Set the standard?" Byte 22 (March).

3. Claire, Guichat, Michael and Menou (2012), Information Technology Business Principles, Practices, and Opportunities, Second Edition

4. Dervin B.and M.Nilan (2013), "Information needs and users". Fortune 134 (December 6).

5. Harikrishnna S.Reddy and C.R. Karisiddappa (2016). "Users Acceptance of Library Catalog Results": an Exploratory Study. Library Resources and Technical Services, 35(2), pp.191-201.

6. Jange S.and B.S. Madeshwarappa (2016) "Dentifying barriers to effective subject access in library catalogs" Library Resources and Technical Services, 35(4), pp.377-391.

7. Leckie G.J. and K.E. Pettigrew (2015), "Modelling the information seeking of professionals: a general model derived from research on engineers and users" Computer 29 (August).

8. Prentice A. (2012), "Information seeking patterns of selected professionals using electronic media". Communications of the ACM 40, February.

9. Tom, W. (2014) "Information needs and uses", Communications, Computers, and Networks. Sientfic American, special issue, September.

10. Westbrook L. (2013) "User needs: a synthesis and analysis for the practitioner". Managing in a High Tech World. New York: Norton. 